03

\title{
Экспериментальная модель - роль трещин в механизме взрывного извержения вулкана St. Helens-80
}

\author{
() В.К. Кедринский, А.А. Скулкин
}

Институт гидродинамики им. М.А. Лаврентьева СО РАН, 630090 Новосибирск, Россия

e-mail: kedr@hydro.nsc.ru

(Поступило в Редакцию 25 ноября 2016 г.)

Создана уникальная мини-модель взрывного извержения вулкана через сформированную систему трещин. Процесс формирования и развития трещин моделируется электровзрывом проводника в погруженной в воду пластине оптически прозрачного плексигласа. Взрыв размещенной соосно со сквозным отверстием в пластине проволочки позволяет генерировать ударно-волновое нагружение вдоль пластины и формировать трещины. Показана принципиальная роль высокоскоростного потока, направленная на расклинивание трещин мощным гидродинамическим потоком пульсирующей взрывной полости.

DOI: 10.21883/JTF.2017.07.44670.2110

\section{Введение}

С разрушением твердых сред развивающимися трещинами при их динамическом нагружении связаны многие физические, технологические и природные процессы. Среди последних большой интерес представляют взрывные вулканические извержения. В [1] показано, что некоторые вулканы взрывного типа могут рассматриваться в качестве сложных гидродинамических систем, включающих камеру вулкана, канал, герметически закрытый пробкой, и систему трещин-dikes, заполненных магмой под высоким давлением. Предполагается, что подобная система характерна для архитектуры вулкана St. Helens, в которой система камера-канал с физической точки зрения аналогична гидродинамической ударной трубке $[2,3]$. Взрывное извержение этого вулкана в мае 1980 г. инициировалось сходом гигантской лавины и отличалось системой циклических выбросов облаков пепла из центрального канала и вдоль траектории оползня. В [4] был предложен механизм генерации последовательности выбросов серии гигантских облаков пепла, основанный на предположении о раскрытии (под действием расклинивающего давления магмы) трещин (dikes) в результате изменения статического давления после схода гигантской лавины с горы St. Helens.

При исследовании этих процессов большую роль играют экспериментальные постановки и лабораторные методы моделирования, позволяющие детально исследовать механизмы, определяющие природу сопровождающих их явлений. Одним из эффективных методов лабораторного исследования динамики формирования и развития трещин являются методы ударно-волнового нагружения при микросекундных временах нагружения [5], основанные на генерации в исследуемом образце короткого импульса сжатия. Трещиностойкость органического стекла при динамическом нагружении [6], влияние наносекундного диапазона длительности воздействия [7] и волновая динамика в твердых диэлектриках при электровзрывном нагружении $[8,9]$ исследовались с точки зрения установления определенных закономерностей, связанных с формированием и развитием трещин.
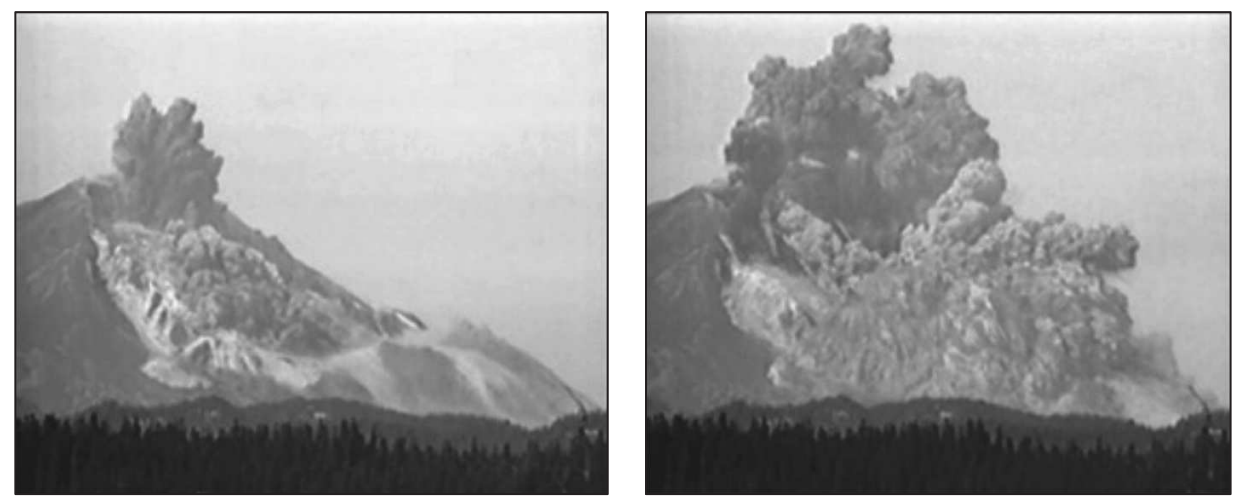

Рис. 1. Две серии выбросов облаков пепла при извержении St. Helens-80: вертикальный выброс (основной канал, левый кадр) и серия боковых выбросов (правый кадр). 
$a$

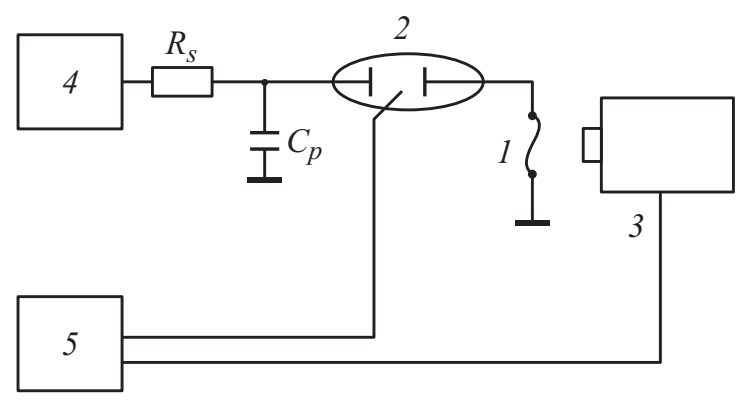

$b$

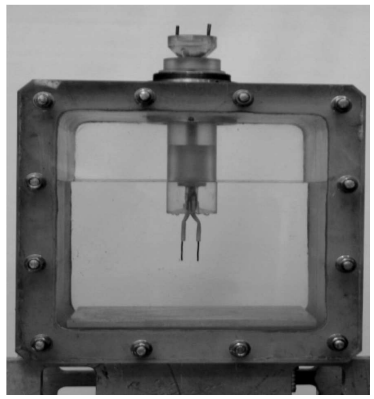

$c$

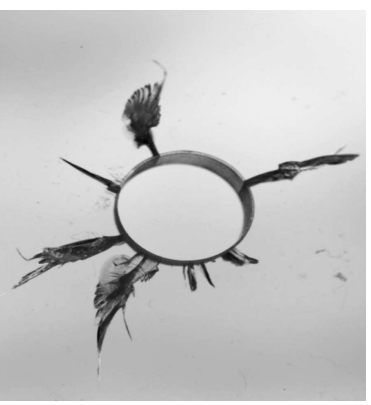

Рис. 2. Принципиальная схема установки: $a-$ электрическая схема, $b-$ заполненный водой взрывной блок, $c-$ типичная система трещин в пластине при взрывном нагружении.

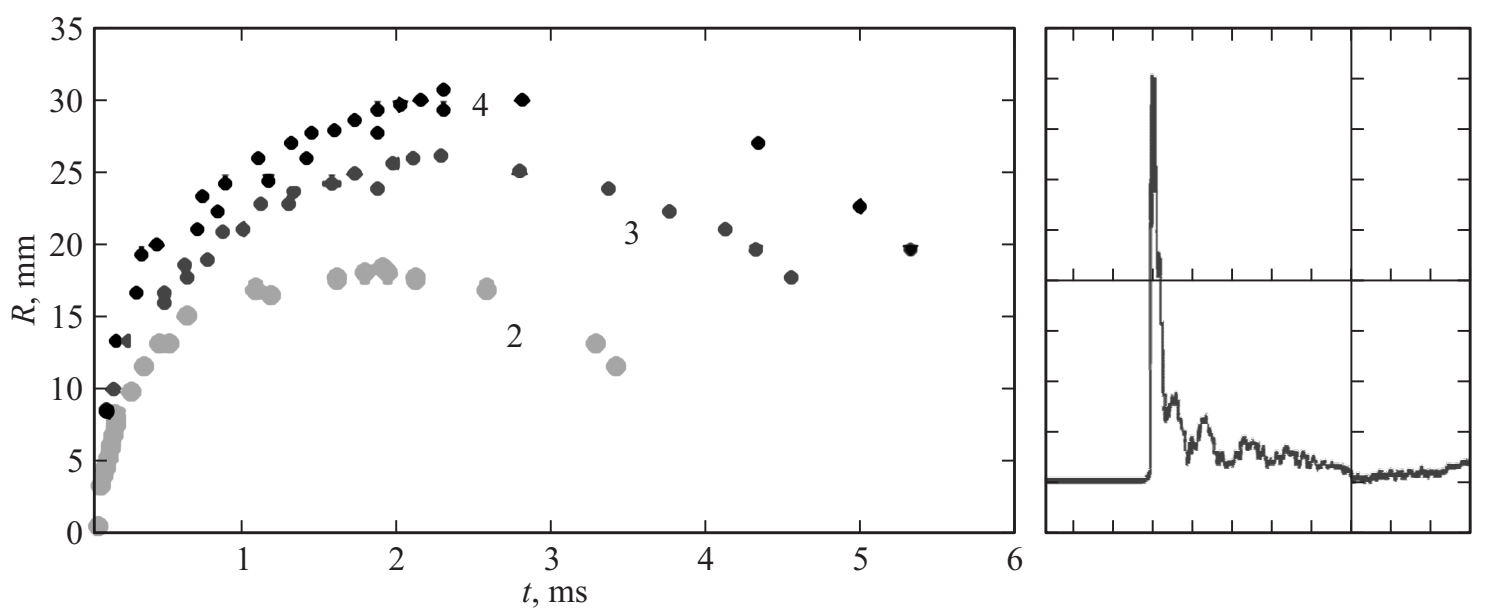

Рис. 3. Динамика взрывной полости при нагружениях 2,3 и $4 \mathrm{kV}$. Характерная осциллограмма давления: $10 \mu \mathrm{s} /$ роint, амплитуда $9 \mathrm{MPa}$.

Нас интересует импульс нагружения, в роли которого выступает ударная волна (УВ), создающая трещины, и формирующаяся пульсирующая взрывная полость, создающая расклинивающий эффект путем внедрения под большим давлением жидкость в трещины [10]. Здесь предложена уникальная постановка, связанная с инициированием УВ, воздействующей на внутреннюю поверхность сквозного кольца в пластине оргстекла при подводном взрыве проволочки, расположенной вдоль оси отверстия перпендикулярно поверхности пластины.

\section{Экспериментальная модель формирования и развития трещин}

Предлагаемые исследования посвящены экспериментальному моделированию данного процесса, основанному на использовании метода электровзрыва проводника в жидкости, позволяющего управлять формированием трещин и их развитием в образцах пластины оптически прозрачного плексигласа (ПММА). Пластина со сквозным отверстием позволяет генерировать УВнагружение вдоль пластины в результате взрыва проволочки, размещенной соосно с отверстием. Упомянутое извержение вулкана St. Helens (май 1980) отличается особым случаем предвзрывного состояния - сходом гигантской лавины, которая сорвала с жерла вулкана „крышку“, инициируя таким образом его извержение из вертикального канала (кондуита) (рис. 1, левый кадр). Сместившаяся к подножию горы гигантская масса грунта существенно уменьшила давление на грунт, что могло привести к раскрытию связанных с камерой вулкана системы трещин-dikes. Их раскрытие в окрестности подножия купола, случайный характер последовательных выбросов нескольких гигантских облаков пепла вдоль траектории схода лавины (рис. 1, правый кадр) и, как следствие, последующее замыкание трещин становится вполне реальным, если учесть отсутствие следов в виде цепочки восстанавливающихся ,пробок“ [3].

Экспериментальное моделирование механизма цикличности извержения вулкана St. Helens основано на методе ударно-волнового нагружения в жидкости пластин из оргстекла с отверстием. Лабораторное моделирование эффекта выполнялось на стенде (рис. 2,a), включающем высоковольтную батарею конденсаторов $C_{p} \mathrm{c}$ накопительной энергией до $200 \mathrm{~J}$, систему зарядки 4 и синхронизации 5, высокоскоростную цифровую видео- 
$a$

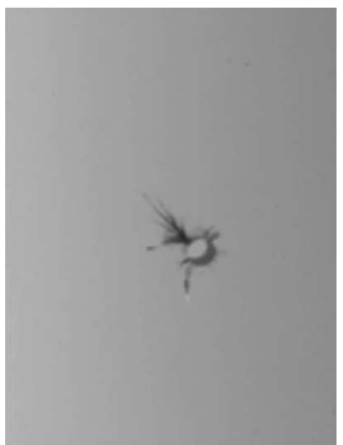

$b$

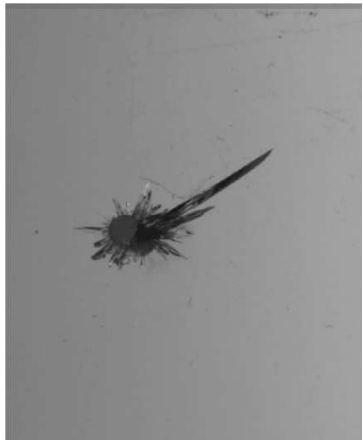

$c$

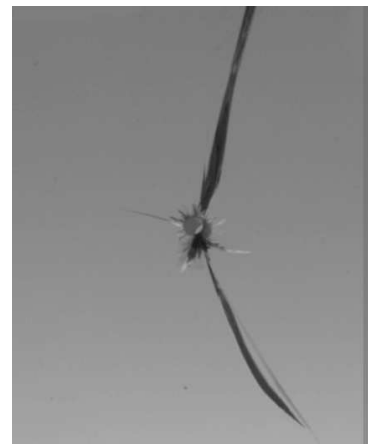

$d$

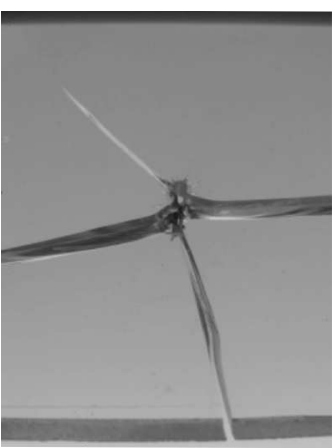

Рис. 4. Влияние интенсивности нагружения на структуру системы трещин.

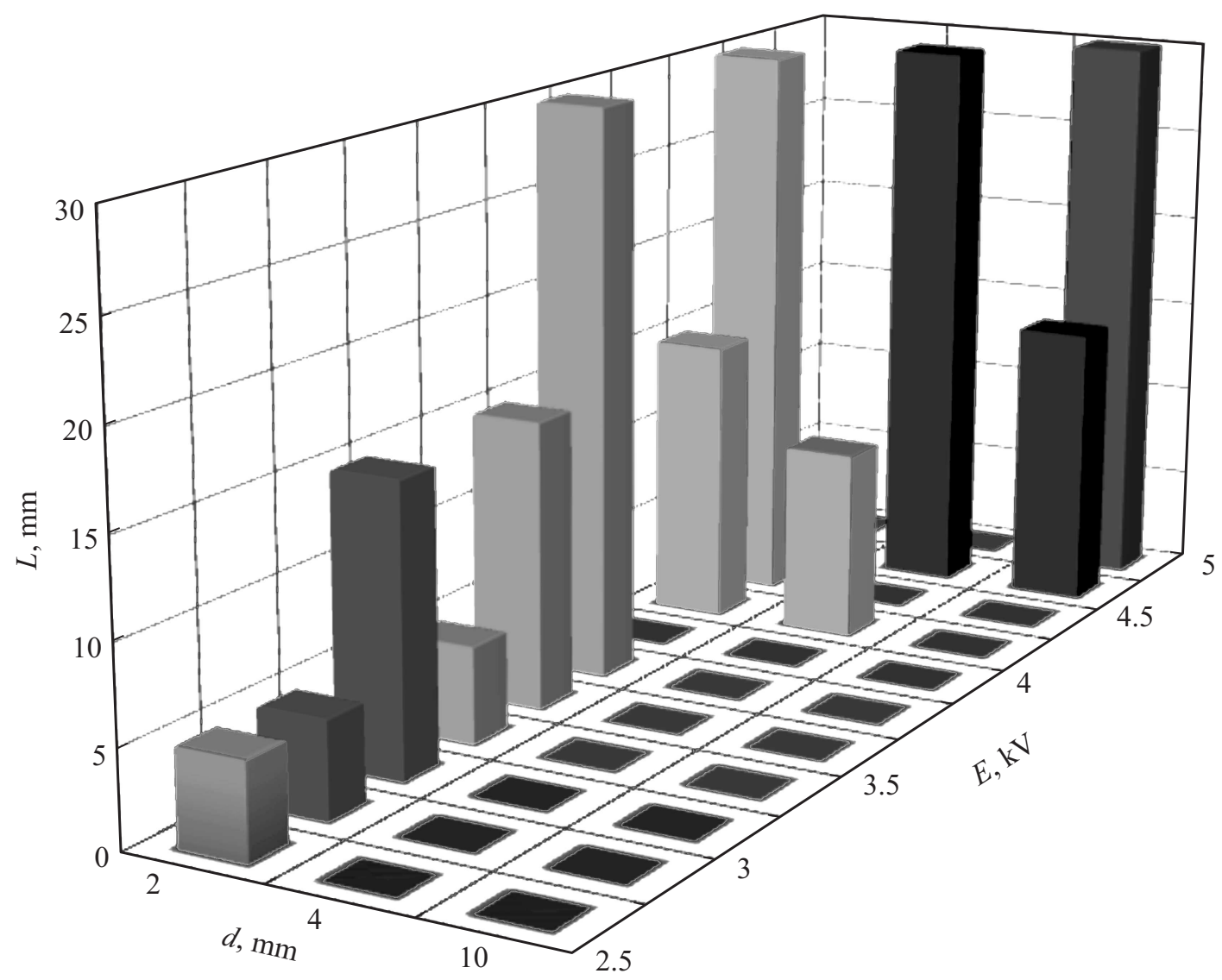

Рис. 5. Для трех размеров отверстий 2,4 и $10 \mathrm{~mm}$ представлены данные по зависимости длины трещин $L$, $\mathrm{mm}$ от интенсивности нагружений.

камеру 3 до 700 тысяч кадров в секунду и рабочую камеру (рис. 2, a (2), рис. 2,b). Между электродами последней фиксировалась пластинка оптического оргстекла $(60 \times 50 \times 4.5 \mathrm{~mm})$ со сквозным цилиндрическим отверстием (рис. 2,c). Исследования формирования трещин, развивающихся в погруженной в воду пластине, проводились на основе оригинального метода, предложенного для генерации вдоль пластины оргстекла ударно-волнового нагружения границы отверстия (коль- цо шириной $4.5 \mathrm{~mm}$ при различных радиусах отверстия) при соосном подводном электровзрыве проволочки.

Экспериментально зарегистрированы параметры газовой полости при подрыве нихромовой проволоки длиной $5 \mathrm{~mm}$ в баке с водой и изменением напряжения на обкладках конденсаторной батареи емкостью $C_{p}=10 \mu \mathrm{F}$ в интервале от 2 до $4 \mathrm{kV}$. Процесс динамики пузыря регистрировался высокоскоростной камерой с частотой съемки $6 \cdot 10^{4}$ кадров в секунду. В результате исследо- 


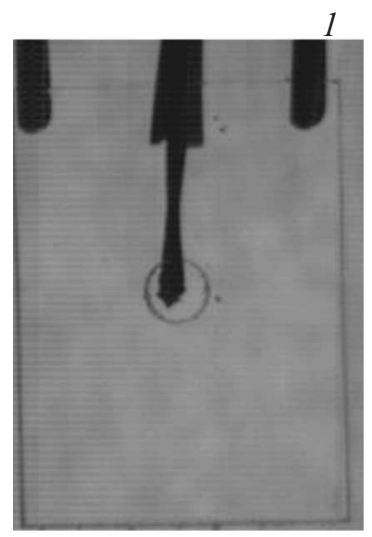

$0 \mathrm{~ms}$

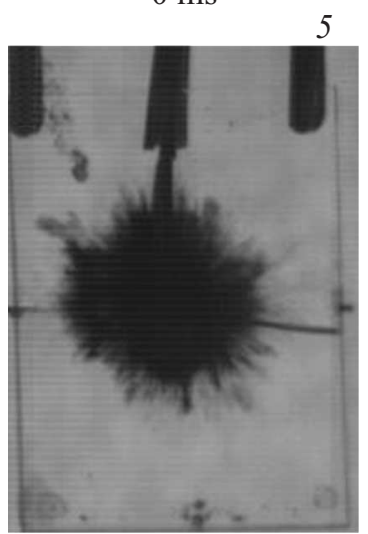

$5.63 \mathrm{~ms}$

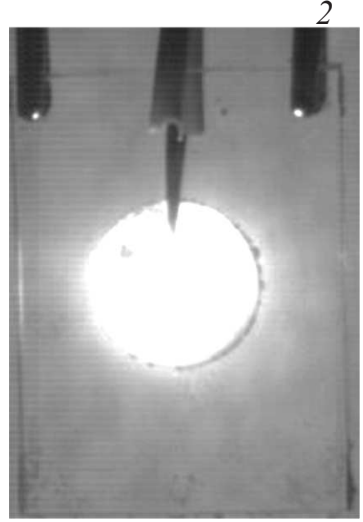

$0.17 \mathrm{~ms}$

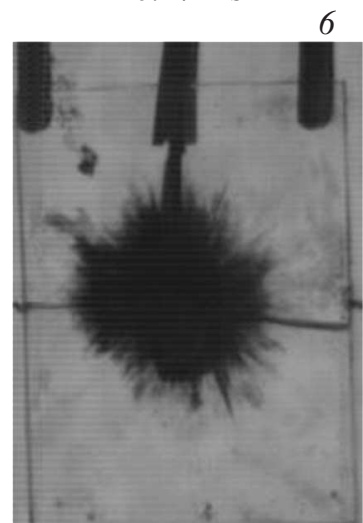

$5.72 \mathrm{~ms}$

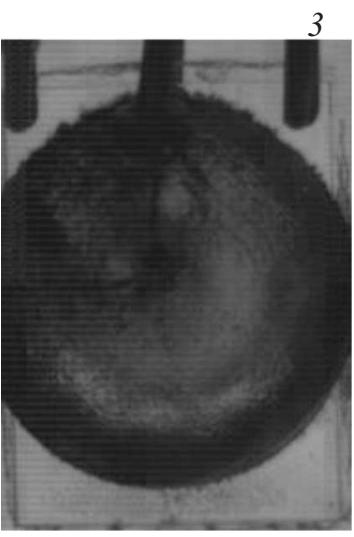

$2.08 \mathrm{~ms}$

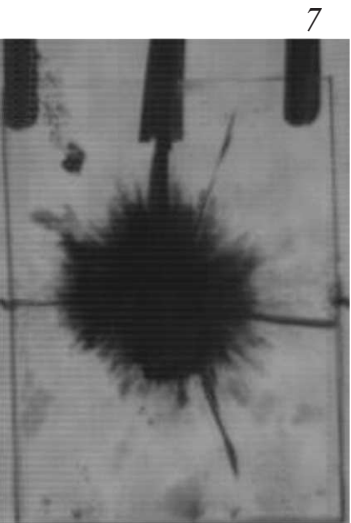

$5.76 \mathrm{~ms}$

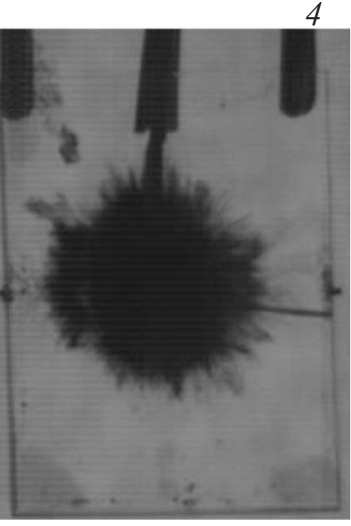

$5.53 \mathrm{~ms}$

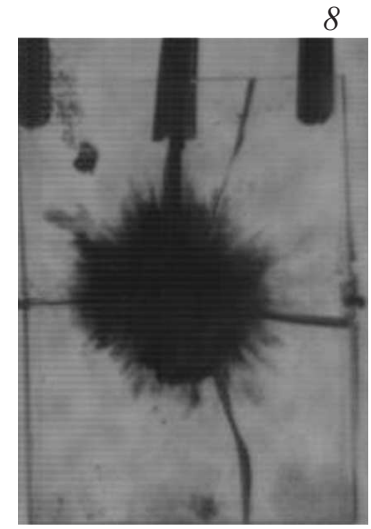

$5.8 \mathrm{~ms}$

Рис. 6. Диаметр отверстия $10 \mathrm{~mm}$, интенсивность нагружения $125 \mathrm{~J}$.

\section{Таблица}

\begin{tabular}{c|c|c|c|c|c|c}
\hline$L, \mathrm{~m}$ & $U, \mathrm{kV}$ & $R_{\max }, \mathrm{m}$ & $T_{\max }, \mathrm{s}$ & $P_{0} V_{\max }, \mathrm{J}$ & $E, \mathrm{~J}$ & КПД, \% \\
\hline 0.005 & 2 & 0.018 & 0.0018 & 2.95 & 20 & 14.75 \\
0.005 & 3 & 0.025 & 0.0026 & 7.524 & 45 & 16.72 \\
0.005 & 4 & 0.03 & 0.0029 & 12.72 & 80 & 15.9
\end{tabular}

ваний построена динамика полости для трех значений энергий в накопителе (рис. 3), а также определена доля энергии, выделившаяся в продуктах взрыва (условно КПД). Полученные данные представлены в таблице.

Исследования динамики взрывной полости показали, что энергия, выделяющаяся в продукты взрыва, составляет 14.7-16.7\% от энергии накопителя. Ударная волна формирует систему трещин, а высокоскоростной поток расширяющейся или схлопывающейся полости с продуктами взрыва - динамическую нагрузку на трещины и их расклинивание. Динамика пульсации взрывной полости при различных нагружениях 2,3 и $4 \mathrm{kV}$ представлена на рис. 3 при характерной осциллограмме давления $P_{\max }=9 \mathrm{MPa}$ и $10 \mu \mathrm{s} /$ point на расстоянии около $5 \mathrm{~cm}$ от взрывающейся проволочки (при нагружении $3 \mathrm{kV}, 45 \mathrm{~J}$ ) представлена в открытом пространстве без пластины.

\section{Формирование трещин}

В результате выполненных экспериментальных исследований найдены характерные структуры систем трещин, определяемые интенсивностью нагружения и размером отверстия. Показана возможность анализа и управления процессами зарождения, формирования и расклинивания трещин. Так, как и предполагалось, влияние УВ и полости с продуктами взрыва на формирование системы трещин можно разделить, ограничивая диаметр отверстия в пластине. Характерный пример представлен на рис. 4 для 2-mm отверстия. Рис. $4, a-d$ соответствуют изменению напряжения источника от 2.5 до $4.0 \mathrm{kV}$ c шагом $0.5 \mathrm{kV}$.

Несложно видеть, что уже при $3 \mathrm{kV}$ УВ генерирует в свободно погруженной в воду пластинке в основном магистральные трещины. Интересно отметить, что при больших диаметрах зоны нагружения и предельных (для используемых условий) интенсивностях УВ-нагружений размер зародышевых трещин, генерируемых в пластине оргстекла, незначителен. Относительно полная картина, связывающая два основных параметра исследований диаметр отверстия $d$ в пластине и интенсивность нагружений (через напряжения $U$ на обкладках конденсаторов), представлена на рис. 5, где показаны данные по динамике размеров трещин $L$ в зависимости от 


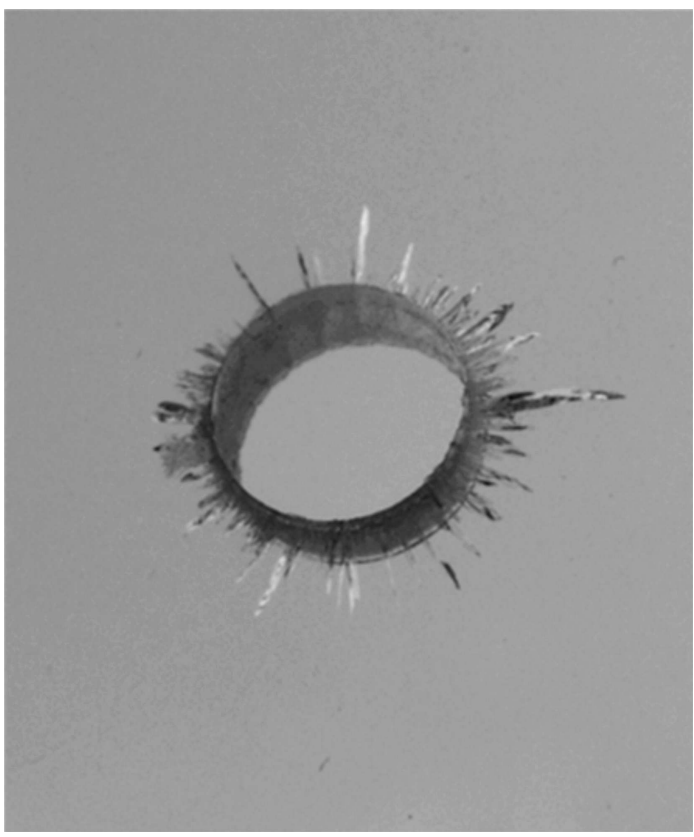

First pressurization

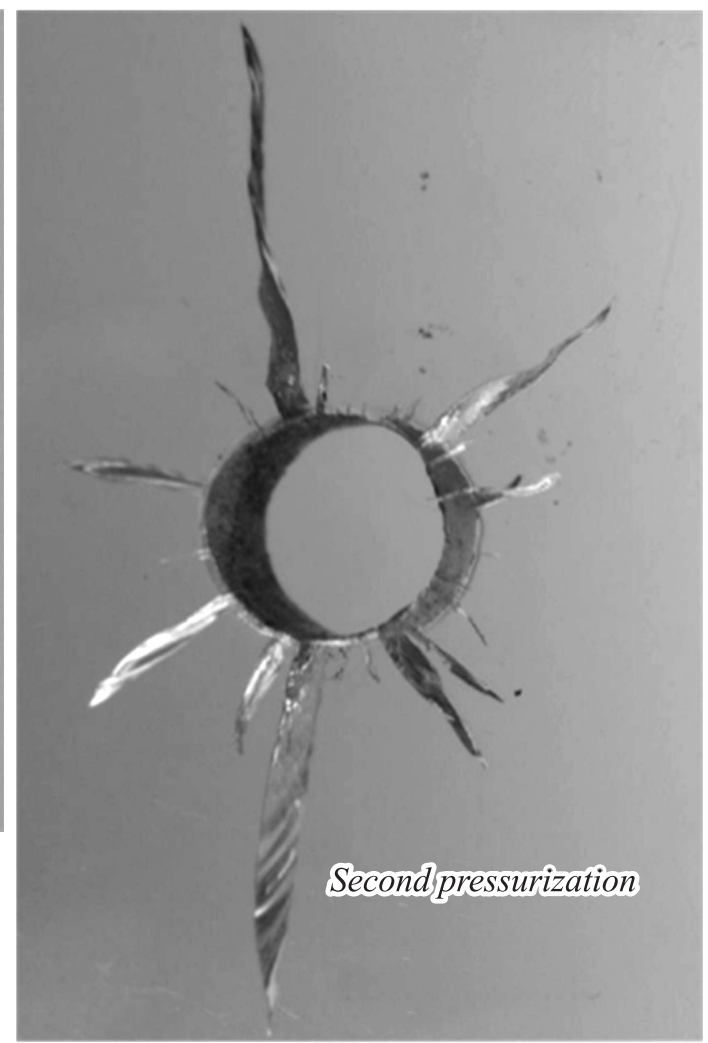

Рис. 7. Создание трещин-dikes серией повторных нагружений $(3 \mathrm{kV}, 10 \mathrm{~mm}$, закрытая кювета).

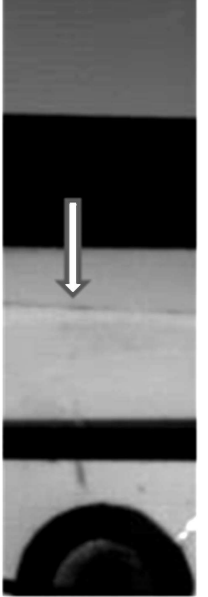

$0 \mathrm{~ms}$

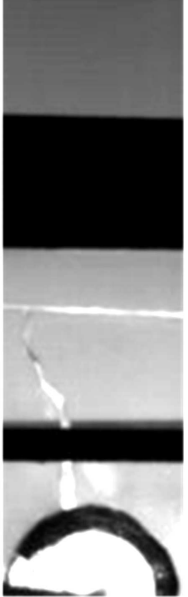

$0.132 \mathrm{~ms}$

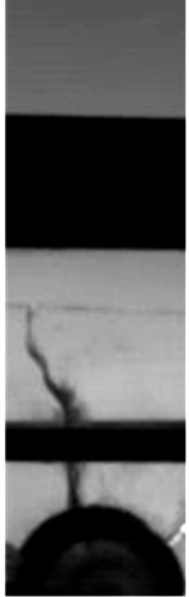

$0.264 \mathrm{~ms}$

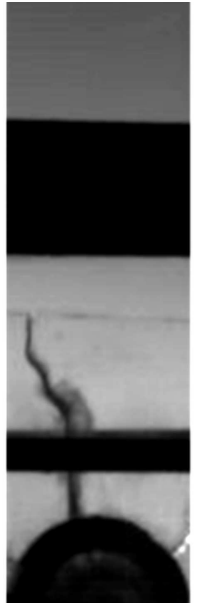

$0.462 \mathrm{~ms}$

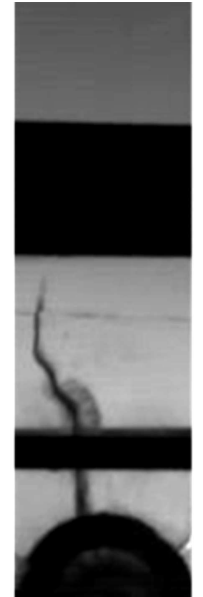

$0.594 \mathrm{~ms}$

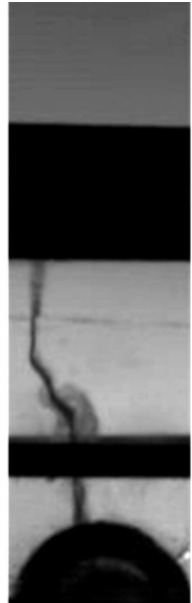

$1.122 \mathrm{~ms}$

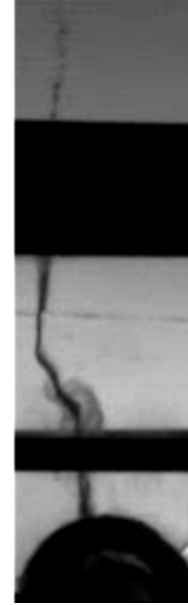

$2.376 \mathrm{~ms}$

Рис. 8. Взрыв при $t=0.132 \mu \mathrm{s}$ (частичная засветка кюветы и трещины), развитие трещины, ее раскрытие на границе пластины (указывает стрелка) и выброс жидкости в атмосферу.

интенсивности входных напряжений на батарее конденсаторов и радиуса отверстия в пластине. Заметим, самые длинные трещины, представленные на рис. 5, это раскрывшиеся на границах исследуемых пластин магистральные трещины.

Как следует из эксперимента, представленного на рис. 6, в формировании больших трещин основную роль может играть вторая фаза (здесь $t=2.08 \mu \mathrm{s}-$ еe начало) подводного взрыва - сходящийся поток, образованный схлопывающейся полостью. Возможно, здесь комплексное влияние оказывают и сильная неустойчивость, которая может привести к образованию (вместо полости) высокоплотного двухфазного потока типа кластера, и значительное повышение давления. Первые 3 кадра на рисунке представляют начальное положение проволочки перед взрывом, светящиеся продукты взрыва 
расширяющейся взрывной полости и ее максимальный размер. На рис. 6 видно, что интенсивное расклинивание и соответственно динамическое нагружение зародышевых трещин возникает, когда диаметр „полостикластера“ с абсолютно неустойчивой границей уменьшается примерно в 2 раза. По принципу часовой стрелки динамику появления и развития трещин можно представить в следующей последовательности: 0-16 (5.53 $\mu \mathrm{s})$, в $5.63 \mu \mathrm{s}$ добавляется трещина $0-45$, в следующих трех кадрах можно четко наблюдать формирование, развитие и расклинивание еще двух трещин - 0-05 и 0-25 с выходом на границу пластины.

\section{Мини-модель St. Helens с системой трещин}

Изложенные детальные результаты являются базовыми при использовании описанного метода для создания экспериментальной мини-модели вулканической камеры вулкана St. Helens с системой трещин-dikes. В качестве модели предложена оригинальная конструкция, включающая пластину оптического оргстекла с отверстием, которая через систему уплотнений зажимается между толстыми прозрачными боковыми стенками оргстекла c соосной с кюветой системой ввода электрических контактов, проволочки и заполнения замкнутого объема кюветы жидкостью. Следующая задача состоит в создании системы нескольких магистральных трещинdikes, выходящих из кюветы. С этой целью предложен метод последовательного УВ-нагружения стенок кюветы взрывом проволочки. В результате такой подготовки в нашем распоряжении оказывается мини-модель вулканической камеры (кюветы) с системой трещин-dikes, базовая структура которой демонстрируется на рис. 7. На этом рисунке показан результат двойного нагружения замкнутой системы: система трещин после первого нагружения - множество мелких трещин миллиметрового диапазона, которая после аналогичного второго нагружения трансформировалась в систему магистральных трещин произвольной длины и ориентации. Эта последняя структура и была использована для финального эксперимента по моделированию щелевого извержения. На основе экспериментальных исследований выбран оптимальный вариант запасенной энергии в накопителе и размера кюветы ( $3 \mathrm{kV}$ при отверстии $10 \mathrm{~mm})$.

Следует напомнить, что сам метод УВ нагружения является уникальным, так как состояние предвзрывного извержения жидкости в кювете создается ударной волной, а динамический напор расширяющейся полости формирует процесс раскрытия трещин. При достаточной энергии нагружения система трещин будет достигать границы пластины, раскрываться и выбрасывать жидкость в атмосферу (рис. 8). Рисунок демонстрирует только верхнюю часть исходной системы трещин. Стрелка указывает верхнюю границу пластины кюветы, на которой происходит раскрытие трещины и выброс, который, как видно из последнего $(t=2.376 \mu \mathrm{s})$ из представленных кадров, выходит за границу сборки мини-модели вулканической камеры с трещинами.

\section{Заключение}

Результаты представленных экспериментальных постановок подтвердили эффективность предложенного метода, при котором раскрытие трещин на границе пластины происходит в различные моменты времени и определяется механизмами независимых процессов развития трещин, произвольными задержками их выхода на границу пластин и случайными моментами их раскрытия. Выбросы облаков пепла в результате щелевых извержений вдоль траектории гигантской лавины, существенно снизившей давление на систему трещин, вполне может рассматриваться как один из возможных механизмов формирования случайных боковых выбросов вулкана St. Helens-80.

Финансовая поддержка обеспечивалась РФФИ (грант № 15-5-003336) и частично Проектом СО РАН III.22.3.1.

\section{Список литературы}

[1] Kedrinskii V.K. Hydrodynamic aspects of explosive eruptions of volcanoes: simulation problems. Shock waves. Vol. 18. N 6. February 2009. P. 451-464.

[2] Eichelberger J., Gordeev E., Koyaguchi T. A RussianJapan-US Partnership to Understand Explosive Volcanism. http://www.uaf.edu/geology/ PIRE.pdf. Jun. 22. 2006. P. 1-4.

[3] Gonnermann H.M., Manga M. // Nature. 2003. Vol. 426. P. 432-435.

[4] Kedrinskii $V$. Explosive eruptions of volcanos: simulation, shock tube methods and multi-phase mathematical models (plenary lecture) // Proceed. Vol. 1. 26 ${ }^{\text {th }}$ International Symp. on Shock Waves. / Eds K. Hannermann, F. Seiler, Goettingen, Germany. Springer, 2007. P. 19-26.

[5] Златин Н.А., Пугачев Г.С., Воловеи, Л.Д., Леонтьев С.А. // ЖТФ. 1981. Т. 51. Вып. 7. С. 1507-1514.

[6] Ефимов В.П., Шер Е.Н. // Прикладная механика и техническая физика. 2001. № 5. С. 217-225.

[7] Петров Ю.В., Смирнов И.В., Уткин А.А. // Изв. РАН. Механика твердого тела. 2010. № 3. С. 200-210.

[8] Буркин В.В., Кузнецова Н.С., Лопатин В.В. // ЖТФ. 2009. Т. 79. Вып. 5. С. 42-48.

[9] Смирнов И.В., Судьенков Ю.В. // ЖТФ. 2011. Т. 81. Вып. 12. С. 114-117.

[10] Скулкин А.А., Кедринский В.К. Механизм периодического выброса взрывного извержения вулкана St Helens: экспериментальная модель и роль трещин // Тезисы статей в трудах Всероссийской конференции по новым математическим моделям механики сплошных сред, конструкций и исследованиям. В честь 95-летия акад. РАН Л. Овсянникова. 18-22 Апреля. 2014. Новосибирск, СО РАН, Институт гидродинамики, Апрель 2014. 